\title{
Mesenchymal Tumors and Lymphoproliferative Diseases of the Stomach and Duodenum
}

\author{
Tanmay Andhalgaonkar ${ }^{1} \quad$ Rakesh Sinha ${ }^{1, \odot}$ \\ 1Department of Clinical Radiology, South Warwickshire NHS \\ Foundation Trust, Warwick, United Kingdom
}

\begin{abstract}
Address for correspondence Rakesh Sinha, MD, FRCR, FICR, South Warwickshire NHS Foundation Trust, Warwick CV34 5BW, United Kingdom (e-mail: rakesh.sinha@swft.nhs.uk).
\end{abstract}

\begin{abstract}
Keywords

- duodenum

- lymphoma

- stomach

Neoplasms of the stomach are classified into two large categories on the basis of the cell of origin: epithelial and nonepithelia. The vast majority of both benign and malignant tumors of the stomach are of epithelial origin, with mesenchymal and neuroendocrine tumors being much less common. The epithelial tumors arise from the mucosa while the nonepithelial tumors arise from the submucosa, muscularis propria, or serosa. The nonepithelial or intramural tumors of stomach include gastrointestinal stromal tumors, leiomyomas, schwannoma, granular cell tumors, glomus tumor, leiomyosarcoma, Kaposi sarcoma, lymphoma, and others. In this review, radiological appearance of mesenchymal tumors and lymphoproliferative tumors are described.
\end{abstract}

\section{Introduction}

Neoplasms of the stomach are classified into two large categories on the basis of the cell of origin: epithelial and nonepithelial..$^{1,2}$ The vast majority of both benign and malignant tumors of the stomach are of epithelial origin, with mesenchymal and neuroendocrine tumors (NET) being much less common. The epithelial tumors arise from the mucosa while the nonepithelial tumors arise from the submucosa, muscularis propria, or serosa.

The nonepithelial or intramural tumors of stomach include gastrointestinal (GI) stromal tumors (GISTs), leiomyomas, schwannoma, granular cell tumors, glomus tumor, NET, leiomyosarcoma, Kaposi sarcoma, lymphoma, and others. ${ }^{1}$ The duodenum is a common site for small bowel tumors accounting for $20 \%$ of these neoplasms. They are classified into benign and malignant categories. The benign tumors seen involving the duodenum are GISTs, lipomas, and adenomas, whereas the malignant primary neoplasms include adenocarcinomas that are epithelial in origin while the nonepithelial or intramural tumors include lymphoma, paraganglioma, and secondary tumors. ${ }^{3}$

published online February 15, 2021
DOI https://doi.org/ $10.1055 / \mathrm{s}-0040-1722794$ ISSN 2581-9933.
Patients with mesenchymal tumors can be asymptomatic independent of the location, if large enough may cause gastric hemorrhage and present with vague symptoms like abdominal pain or mass. Very rarely they cause obstruction or intussusception.

Mesenchymal tumors are often well circumscribed, with intact overlying mucosa except in larger tumors ( $>2 \mathrm{~cm}$ in size), the overlying mucosa can be ulcerated due to necrosis. They grow in exophytic, endoluminal, or mixed pattern giving dumbbell-shaped appearance.

Because of various overlapping features, differentiating between these tumors can be challenging. However, the combination of features like margins, location, growth pattern, and enhancement may help in narrowing down the differential diagnosis. In this article, we review the radiological features of the mesenchymal and lymphoproliferative tumors of stomach and duodenum ( - Table $\mathbf{1})$.

\section{Imaging Technique}

Intramural tumors are quite often diagnosed incidentally. However, whenever dedicated evaluation of stomach and (C) 2021. Indian Society of Gastrointestinal and Abdominal Radiology.
This is an open access article published by Thieme under the terms of the Creative
Commons Attribution-NonDerivative-NonCommercial-License, permitting copying
and reproduction so long as the original work is given appropriate credit. Contents
may not be used for commercial purposes, or adapted, remixed, transformed or
built upon. (https://creativecommons.org/licenses/by-nc-nd/4.0/).
Thieme Medical and Scientific Publishers Pvt. Ltd. A-12, 2nd Floor,
Sector 2, Noida-201301 UP, India 
duodenum is required, adequate distention with sufficient quantities of radiopaque oral contrast should be achieved to differentiate between small tumors and thickened gastric rugae. Bicarbonate granules can also be used which distend stomach and duodenum through release of $\mathrm{CO}_{2}{ }^{3}$ On barium meal examination, these intramural tumors reveal intact and smooth mucosal surface forming obtuse angle with the stomach wall and as a filling defect. A CT scan is routinely performed in these patients as the fluoroscopy has limitations in evaluation of extraluminal extension of these masses.

On CT evaluation, the gastric distention is usually achieved by using oral contrast. A negative oral contrast (like water) is used if mucosal enhancement is to be evaluated ( - Fig. 1). During CT examinations, up to $200 \mathrm{~mL}$ of enteral contrast should be administered just prior to scanning to outline and distend the stomach and duodenum. The mucosal enhancement can be appreciated as a prominent linear enhancement in arterial phase of imaging. In later phases, the gastric wall enhances as a single layer. Hence, a dual phase imaging technique (arterial and portal venous phases) is helpful which also helps in detection of hypervascular lesions or metastatic lesions (particularly GIST or NET). ${ }^{4,5}$

\section{Gastrointestinal Stromal Tumors}

The most common GI mesenchymal neoplasms are GIST. ${ }^{6}$ The term GIST is now used for a specific group of tumors comprising the majority of all GI mesenchymal tumors. GISTs differ from smooth muscle neoplasms in that they are derived from a precursor of the intestinal pacemaker cells of Cajal rather than from smooth muscle cells. ${ }^{7-9}$ They are most common in the stomach (60-70\%), followed by small intestine (20-30\%), colorectum, and esophagus (together $<10 \%$ ). ${ }^{2}$ They can be found in extravisceral locations as well like mesentery, omentum, and retroperitoneum. In the stomach, most common location is body followed by the fundus and then antrum.
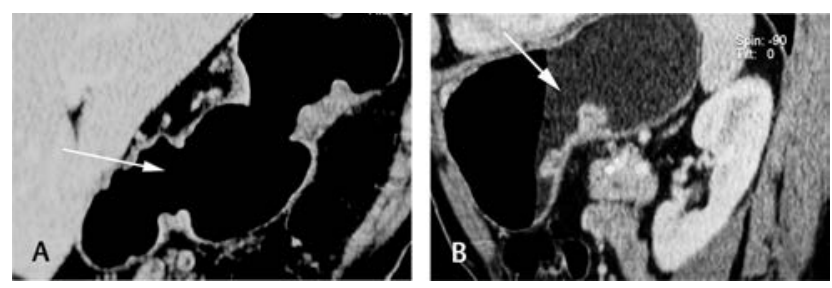

Fig. 1 Gastric computed tomography. (A) Coronal view performed with carbon dioxide causing negative contrast (arrow). (B) With water providing neutral contrast within the gastric lumen (arrow).

Table 1 Imaging features of tumors

\begin{tabular}{|c|c|c|c|c|}
\hline Name of the tumor & Appearance & $\begin{array}{l}\text { Arterial } \\
\text { enhancement }\end{array}$ & $\begin{array}{l}\text { Venous } \\
\text { enhancement }\end{array}$ & Other relevant finding \\
\hline GIST & $\begin{array}{l}\text { Larger lesions may be exophytic, } \\
\text { heterogeneously enhancing with necrosis } \\
\text { Smaller lesions may enhance uniformly }\end{array}$ & $\begin{array}{l}\text { May be present, } \\
\text { particularly in } \\
\text { metastases }\end{array}$ & $\begin{array}{l}\text { Increased } \\
\text { enhancement }\end{array}$ & $\begin{array}{l}\text { CD117 and CD34 positive } \\
\text { May metastasize }\end{array}$ \\
\hline Leiomyoma & $\begin{array}{l}\text { Homogeneous, low-attenuation masses } \\
\text { with an endoluminal growth pattern }\end{array}$ & None & $\begin{array}{l}\text { Homogenous } \\
\text { enhancement }\end{array}$ & Positive for desmin \\
\hline Leiomyosarcoma & $\begin{array}{l}\text { Large, aggressive tumors with } \\
\text { heterogeneous enhancement and areas of } \\
\text { necrosis }\end{array}$ & & $\begin{array}{l}\text { Enhancement } \\
\text { with necrotic } \\
\text { areas }\end{array}$ & $\begin{array}{l}\text { Invasion of adjacent } \\
\text { organs }\end{array}$ \\
\hline Lipoma & $\begin{array}{l}\text { endoluminal, fat density ( }-70 \text { to }-120 \mathrm{HU}) \text {, } \\
\text { arising in the submucosa }\end{array}$ & None & None & $\begin{array}{l}\text { May be pliable or deform } \\
\text { during compression }\end{array}$ \\
\hline Neurogenic tumors & $\begin{array}{l}\text { Well-defined, intramural, or exophytic } \\
\text { lesions }\end{array}$ & & $\begin{array}{l}\text { None or minimal } \\
\text { enhancement }\end{array}$ & $\begin{array}{l}\text { Features of } \\
\text { neurofibromatosis }\end{array}$ \\
\hline Glomus tumors & Solitary, most common in gastric antrum & $\begin{array}{l}\text { Dense arterial } \\
\text { enhancement }\end{array}$ & $\begin{array}{l}\text { Delayed filling } \\
\text { similar to a } \\
\text { hemangioma }\end{array}$ & \\
\hline Kaposi's sarcoma & $\begin{array}{l}\text { Polypoid submucosal masses } 0.5 \text { to } 3 \mathrm{~cm} \text { in } \\
\text { diameter and irregular fold thickening } \\
\text { Target lesions on double contrast } \\
\text { examination }\end{array}$ & & $\begin{array}{l}\text { Usually } \\
\text { homogenous } \\
\text { enhancement }\end{array}$ & $\begin{array}{l}\text { Hyperattenuating } \\
\text { lymphadenopathies }\end{array}$ \\
\hline $\begin{array}{l}\text { Neuroendocrine } \\
\text { tumors (carcinoid) }\end{array}$ & $\begin{array}{l}\text { Type 1: multiple polyps of less than } 2 \mathrm{~cm} \text { in } \\
\text { diameter } \\
\text { Type 2: multiple masses in the setting of } \\
\text { diffuse gastric wall thickening } \\
\text { Type 3: usually solitary submucosal tumors }\end{array}$ & $\begin{array}{l}\text { Hyperenhancing } \\
\text { liver metastasis }\end{array}$ & $\begin{array}{l}\text { Primary lesion } \\
\text { shows venous } \\
\text { enhancement }\end{array}$ & $\begin{array}{l}\text { Primary lesion shows } \\
\text { uptake on Octreotide } \\
\text { scans (Ga-68 DOTATATE) } \\
\text { Type } 1 \text { associated with } \\
\text { autoimmune gastritis and } \\
\text { type } 2 \text { are associated with } \\
\text { MEN-1 }\end{array}$ \\
\hline Hamartomas & Smooth intraluminal lesions & & $\begin{array}{l}\text { Homogenous } \\
\text { enhancement }\end{array}$ & $\begin{array}{l}\text { Genetic testing for Peutz- } \\
\text { Jeghers syndrome }\end{array}$ \\
\hline Lymphoma & $\begin{array}{l}\text { Marked gastric wall thickening, multiple } \\
\text { enlarged enhancing lymph nodes }\end{array}$ & & $\begin{array}{l}\text { Homogenous } \\
\text { enhancement }\end{array}$ & $\begin{array}{l}\text { Other organ involvement } \\
\text { Lymph nodes } \\
\text { Aneurysmal dilatation }\end{array}$ \\
\hline
\end{tabular}

Abbreviation: GIST, gastrointestinal stromal tumor. 
GIST predominantly occurs in middle-aged and older persons (5th to 7th decade), with no significant difference in distribution between males and females. The symptoms, which depend on tumor size and location, are usually nonspecific. The commonest presentation of GIST is bleeding secondary to mucosal erosion by the tumor. ${ }^{10}$

GISTs are characterized by immunoreactivity for c-KIT (CD117), a growth factor receptor tyrosine kinase that is normally expressed on hematopoietic stem cells, mast cells, melanocytes, and the myenteric plexus of the normal adult GI tract. Approximately 70 to $80 \%$ of GISTs are also positive for CD34. ${ }^{2}$ Evaluation of malignancy of GISTs is based on mitotic count, tumor size, and extragastrointestinal spread. Tumors with mitotic counts higher than 5/10 high power fields or larger than $10 \mathrm{~cm}$ have a significant risk for recurrence and metastasis, and are considered histologically malignant. ${ }^{9}$ Histologic characteristics of GISTs usually consist of interlacing whorls of spindle-shaped cells with eosinophilic cytoplasm and elongated nuclei, although tumors completely composed of ovoid cells are not uncommon. Immunoreactivity to c-KIT or DOG1 confirms the diagnosis.

The CT features of GISTs vary greatly, depending on the size and aggressiveness of the tumor and the time of presentation during the course of the disease. Primary GISTs are typically large, hypervascular, and enhancing masses on contrast enhanced CT scans, and they are often heterogeneous because of necrosis, hemorrhage, or cystic degeneration at the time of presentation $^{5,11}$ ( - Fig. 2). Ulceration and fistulization to the GI lumen are also common features of GISTs. Often, tumor vessels can be seen within the tumors. The masses usually displace adjacent organs and vessels; however, direct invasion of the adjacent structures may be rarely seen with advanced disease. Small GISTs can be endoluminal and polypoid in appearance. Small and localized GISTs are usually homogeneous, and may be an incidental finding at CT or endoscopy. Nearly 50\% of patients with GISTs present with metastasis. ${ }^{5}$ Most metastases of GISTs involve the liver and peritoneum by hematogenous spread and peritoneal seeding, respectively. Less commonly, metastases are found in the soft tissue, lungs, and pleura. Calcification within GIST tumors is usually not seen at presentation but may be seen after treatment. ${ }^{5}$

Differential diagnosis of GISTs includes schwannomas, true leiomyomas, and solitary (type 1) carcinoid tumors, particularly for smaller lesions. Occasionally, gastric adenocarcinoma or lymphoma may demonstrate intramural growth and mimic a GIST. However, advanced gastric carcinomas and lymphomas are usually associated with bulky perigastric or celiac lymphadenopathy, which is rare for GISTs.1 GISTs are known to be associated with neurofibromatosis. ${ }^{12}$

\section{Leiomyoma and Leiomyosarcoma}

Well-documented true gastric leiomyomas and leiomyosarcomas are very infrequent. Older literature referred to GISTs as leiomyomas; however, true leiomyomas as well as leiomyosarcomas are negative for c-KIT and strongly and diffusely positive for desmin and smooth muscle actin. ${ }^{13}$ Leiomyosarcoma lesions are usually large, aggressive tumors with heterogeneous enhancement and areas of necrosis. Their appearance is nonspecific, and histologic confirmation is required for diagnosis. It is extremely important to accurately differentiate leiomyomas and leiomyosarcomas from GISTs because GISTs respond favorably to imatinib, whereas leiomyosarcomas have a less predictable response to conventional chemotherapy. Leiomyomas are benign while GISTs are associated with risk of progression and metastasis.

In the stomach, small bowel, and colon, GISTs far outnumber leiomyomas. The esophagus is the only site in the GI tract where leiomyomas predominate. Leiomyomas are almost always seen in the gastric cardia as homogeneous, low-attenuation masses with an endoluminal growth pattern, often ranging from 1.3 to $4.7 \mathrm{~cm}$ in diameter. ${ }^{14}$ Tumors larger than $2 \mathrm{~cm}$ can have central ulceration (-Figs. 3-4).

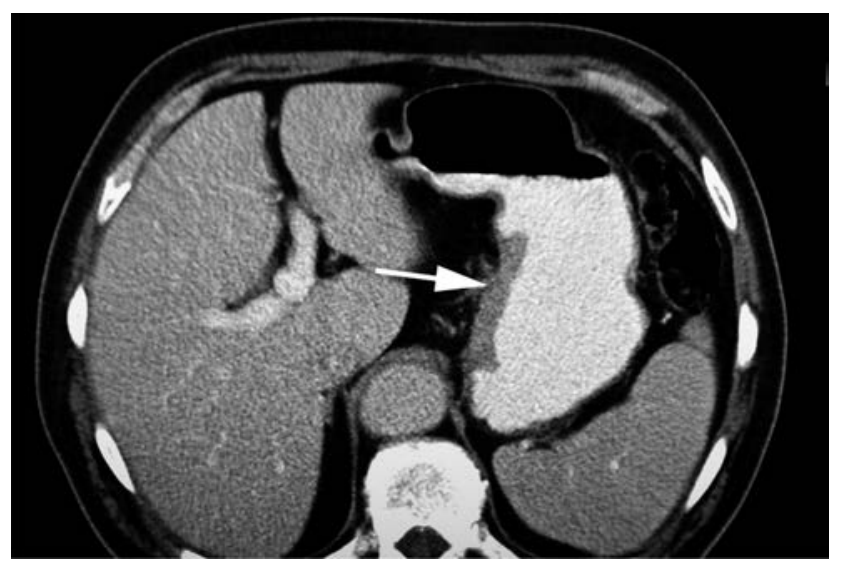

Fig. 3 Leiomyoma seen as a flat, uniformly enhancing lesion with endoluminal projection in the stomach (arrow).
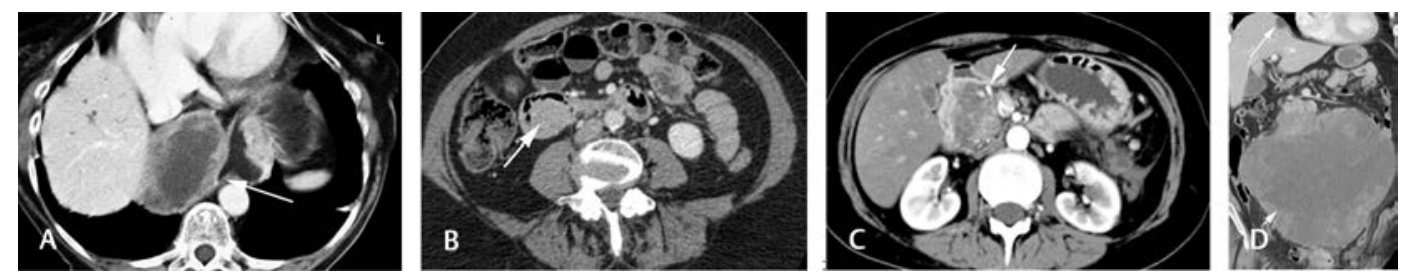

Fig. 2 Gastrointestinal stromal tumors. (A) Typical appearances of a gastric GIST arising from the lesser curvature with eccentric location, central necrosis, and peripheral enhancement (arrow). (B) Small uniformly enhancing, polypoid GIST in the duodenum (arrow). (C) Large duodenal GIST showing submucosal location with central necrosis and peripheral calcification (arrow). (D) Coronal computed tomography image of a large duodenal GIST (short arrow) with a hypodense liver metastases (long arrow). GIST, gastrointestinal stromal tumor. 


\section{Lipomas}

Gastric lipomas are composed of mature fat cells surrounded by a fibrous capsule. ${ }^{15}$ Patients may present with pain, upper GI bleeding, dyspepsia, and/or gastric outlet obstruction, although they are typically asymptomatic when small.

On radiographs, a lipoma can occasionally appear as a radiolucent shadow. During fluoroscopy, a lipoma appears as a smooth well-marginated mass, sometimes with central ulceration. Three-quarters of lipomas are solitary lesions, with the most common location being the gastric antrum. The majority (95\%) of lipomas are endoluminal, arising in the submucosa. On CT images, attenuation values of-70 to-120 HU are diagnostic of a lipoma (-Fig. 5).

\section{Peripheral Nerve Sheath Tumors (Neurogenic Tumors)}

Gastrointestinal schwannomas are rare neoplasms. Gastrointestinal schwannomas are distinctly different neoplasms from conventional soft-tissue and central nervous system schwannomas, some of which may be associated with neurofibromatosis 2. ${ }^{16}$ Gastrointestinal schwannomas occur most commonly in the stomach (60-70\% of cases), followed by the colon and rectum ${ }^{22}$. Esophageal and small-intestinal schwannomas have been rarely reported. At clinical examination, patients may be asymptomatic or present with abdominal pain or GI bleeding (if the tumor is ulcerated). Larger lesions can manifest with obstructive symptoms. There is a female predominance among patients with schwannomas, with a median age
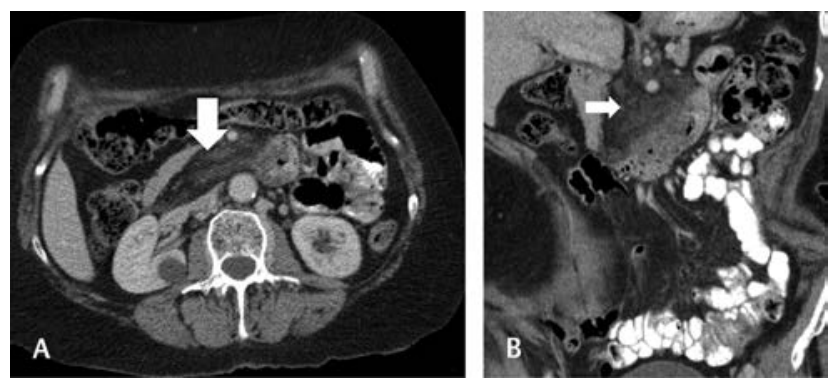

Fig. 4 Leiomyosarcoma. (A) Axial CT image shows a hypodense, poorly enhancing lesion involving the third part of duodenum with adjacent infiltration of retroperitoneum (arrow). (B) Coronal CT image shows the hazy infiltration of retroperitoneal fat (arrow). CT, computed tomography.
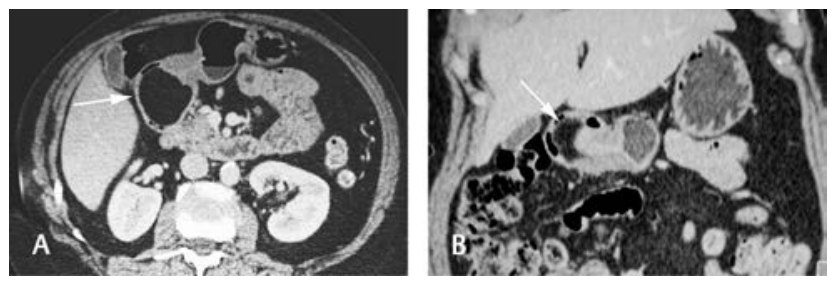

Fig. 5 Lipoma. (A) Shows typical appearance of a fat-attenuation, submucosal lesion in the gastric antrum causing narrowing of the lumen (arrow). (B) Lipoma in the first part of duodenum seen as a fat-attenuation, submucosal lesion. of 60 years. Schwannomas arise most often in the gastric body, demonstrating an exophytic or intramural pattern of growth.

The tumor has low attenuation on CT images because of its dense spindle cell composition. Contrast-enhanced CT may show no or minimal enhancement (-Fig. 6). Although cystic degeneration is a common feature of schwannomas found in other parts of the body, this characteristic is uncommon for gastric schwannomas. ${ }^{17}$

Neurofibromas are rare tumors that arise from the sympathetic nerves of the Auerbach myenteric plexus or, less frequently, the Meissner submucosal plexus. Patients with neurofibromatosis can have multiple neurofibromas and also have increased risk of malignant degeneration.

\section{Glomus Tumor}

Glomus tumors arise from modified smooth muscle cells of the glomus bodies, which are neuromyoarterial receptors commonly seen in the dermis or subcutis of the extremities that regulate body temperature. ${ }^{18}$ Nearly all GI glomus tumors arise in the muscularis propria of the stomach, and they account for $2 \%$ of all benign gastric tumors. Rare malignant tumors have been reported for lesions larger than $5 \mathrm{~cm} .{ }^{18}$

Glomus tumors most commonly manifest as a solitary hypervascular lesion in the gastric antrum and range from 1 to $4 \mathrm{~cm}$ in diameter. ${ }^{18}$ At fluoroscopy, they appear as smooth intramural masses indistinguishable from other mesenchymal tumors. Because they are soft tumors, glomus tumors can change in shape and size during fluoroscopy, similar to lipomas. They are easily differentiated from lipomas on CT images because of their dense arterial phase enhancement, which persists in the delayed phase ( - Fig. 7). A peripheral nodular pattern of enhancement with delayed filling-in, reminiscent of a hemangioma, has been reported as a specific feature of gastric glomus tumors.
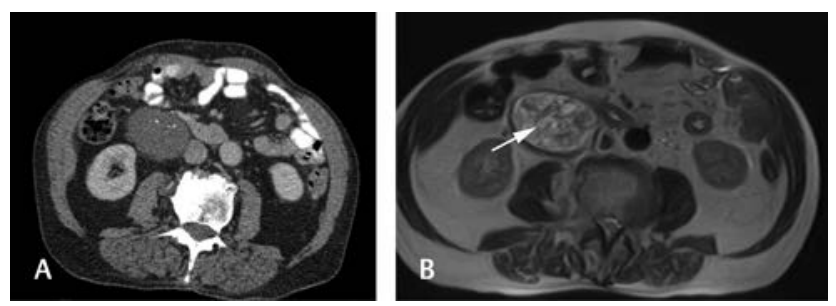

Fig. 6 Schwannoma. (A) A uniformly low attenuation mass is seen at junction of second and third part of duodenum (arrow). (B) Magnetic resonance imaging shows high signal changes within the mass (arrow).
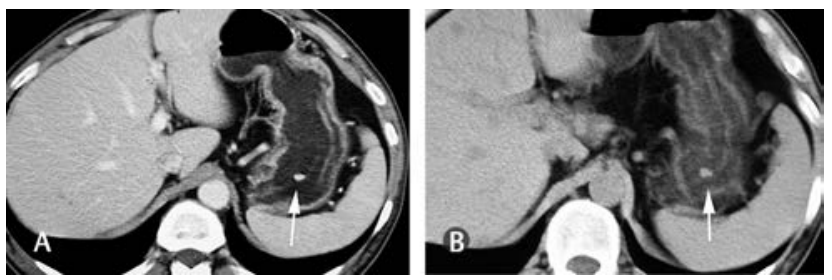

Fig. 7 Glomus tumor. (A) Intense enhancement is seen in a nodular lesion within the body of stomach (arrow). (B) The enhancement persists in the delayed venous phase (arrow) which is typical of glomus tumors. 


\section{Kaposi Sarcoma}

Kaposi sarcoma may occur in the stomach as a mucosal lesion or, less commonly, as a mural mass, usually in HIV positive

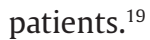

AIDS-related Kaposi sarcoma can affect any level of the GI tract from the oropharynx to the rectum, including the gallbladder. The duodenum is the most frequently affected site. The red-purple endoscopic appearance of lesions is helpful in developing the differential diagnosis, which may include lymphoma, opportunistic infections, hematogenous metastasis, polyps, and Crohn disease. Early disease is frequently asymptomatic, but complications (i.e., bleeding, intestinal and biliary obstruction, intussusception, perforations, diarrhea, and protein-losing enteropathy) may occur as the lesions enlarge.

Double-contrast barium studies may not help detect early flat lesions. Larger lesions are detected as masses with or without central ulceration ("bull's eye" or "target" lesions). ${ }^{19,20}$ Polypoid submucosal masses 0.5 to $3 \mathrm{~cm}$ in diameter, and irregular fold thickening may be detected at cross-sectional imaging (-Fig. 8). After the intravenous injection of contrast material, hyperattenuating lymphadenopathies of the porta hepatis or peripancreatic, retroperitoneal, mesenteric, inguinal, or pelvic hyperattenuating lymphadenopathies may be seen in approximately $80 \%$ of cases of disseminated $\mathrm{KS}^{19}$ Bleeding may be a life-threatening complication, often requiring angiographic diagnosis and treatment.

\section{Neuroendocrine Tumor}

Carcinoid tumors are well-differentiated NETs that originate from the diffuse endocrine system. In the GI tract, the small
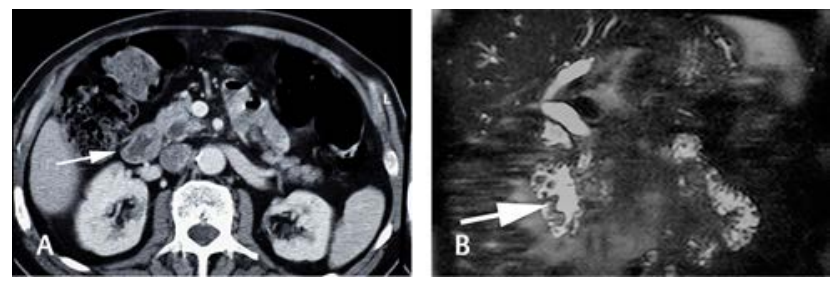

Fig. 8 Kaposi's sarcoma. (A) Axial computed tomography image shows polypoid thickening of the duodenum (arrow). (B) Coronal magnetic resonance imaging HASTE image polypoid changes in the duodenum with some areas showing the bull's eye pattern of ulceration. HASTE, Half Fourier single-shot turbo spin-echo. bowel is the most common location, followed by the rectum, appendix, and stomach. ${ }^{21}$ Gastric carcinoid tumors are rare, accounting for $1.8 \%$ of all gastric malignancies. ${ }^{22}$ Carcinoid tumors usually originate from enterochromaffin-like cells (Kulchitsky cells) in the gastric mucosa and are therefore epithelial in origin.

Of the three types of gastric carcinoids, types 1 and 2 are associated with hypergastrinemia, which causes proliferation of enterochromaffin like cells and thus promotes the development of often multiple carcinoid tumors. ${ }^{23}$ The majority (75-80\%) of gastric carcinoids are type 1 , in which patients have atrophic metaplastic autoimmune gastritis with or without pernicious anemia. Nodal and hepatic metastases are rare in type 1 carcinoid tumors. Type 2 tumors account for 5 to $10 \%$ of gastric carcinoids and are caused by hypergastrinemia from a gastrin-producing tumor in association with multiple endocrine neoplasia (MEN) type 1 . Approximately $30 \%$ of patients with MEN 1 have gastric carcinoid tumors. Type 3 gastric carcinoids (accounting for roughly 13\% of all gastric carcinoids) are sporadic tumors that are not associated with hypergastrinemia.

At radiologic examination, type 1 gastric carcinoid tumors often appear as multiple polyps of less than $2 \mathrm{~cm}$ in diameter in the gastric fundus, although they can be solitary (-Fig. 9). Type 2 carcinoids can appear remarkable because of the presence of multiple masses in the setting of diffuse gastric wall thickening. Unlike type 1 and 2 gastric carcinoids, type 3 tumors are usually solitary submucosal tumors that may show ulceration and that are more likely to be recurrent and invasive with distant metastases. The likelihood of metastasis and perigastric lymphadenopathy depends on tumor size. Prognosis is poor, with $20 \%$ of patients surviving 5 years.

\section{Hamartomas}

Peutz-Jeghers syndrome is a rare autosomal dominant inherited condition and characterized by multiple hamartomatous small bowel polyps, which are composed of smooth muscle and covered by normal mucosa. PeutzJeghers polyps are most often found in the jejunum followed by the ileum and duodenum. The condition is also characterized by mucocutaneous perioral and genital melanin pigmentation, and increased risk of intestinal adenocarcinoma and non-GI tumors.
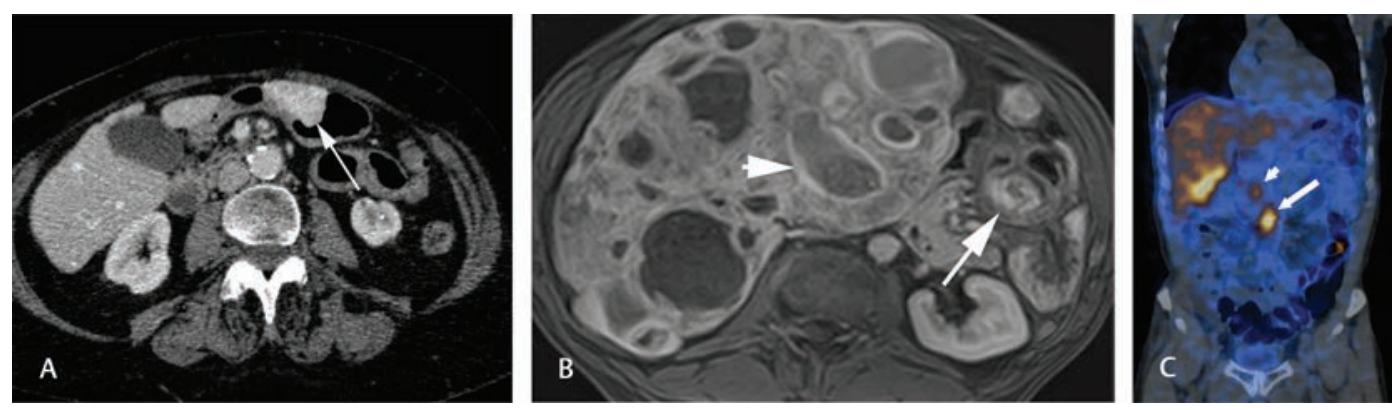

Fig. 9 Neuroendocrine tumors. (A) Computed tomography image shows an arterially enhancing, polypoid lesion in the body of the stomach (arrow). (B) Magnetic resonance imaging image shows a NET in the stomach (arrow) with multiple cystic liver metastases, some of which show haemorrhagic elements (short arrow). (C) Octreotide scan in a patient with duodenal NET shows uptake in the tumor (arrow), lymph nodes (long arrow) and uptake in the liver metastases. NET, neuroendocrine tumor. 
Patients often present with multiple episodes of colicky abdominal pain due to intermittent intussusception and bleeding. At CT or MRI, hamartomas are seen as smooth, uniformly enhancing intraluminal masses the bowel (-Fig. 10).

\section{Lymphoma}

Primary gastric lymphoma represents 1 to $5 \%$ of gastric malignancies. ${ }^{24}$ Gastric lymphoma and is the most common type of extranodal lymphoma and accounts for 50 to $70 \%$ of all primary GI tract lymphomas. ${ }^{24}$ Chronic Helicobacter pylori infection is associated with the development of lowgrade MALT lymphoma, having been reported to account for 50 to $72 \%$ of all primary gastric lymphomas. ${ }^{25,26}$ Primary gastric lymphoma often originates as a low-grade MALT lymphoma and transforms into intermediate or high-grade large cell lymphoma. Low-grade tumors are associated with a 5 -year survival rate of 75 to $91 \%$, compared with a 5 -year survival rate of less than $50 \%$ for patients with highgrade MALT lymphomas.

On barium studies lymphomas may appear as multiple polypoid tumors, especially with central ulceration, giant cavitating lesions, or extensive infiltrative gastric fold thickening. ${ }^{24}$ The stomach remains distensible even in cases with extensive lymphoma involvement, a crucial differential between lymphoma and linitis plastica. On cross-sectional imaging, marked gastric wall thickening is present. There may be preservation of perigastric fat planes and gastric outlet obstruction is rare $^{27}$ (-Figs. 11, 12).

Bulky lymph nodes are more common with lymphoma than adenocarcinoma particularly if they extend below the renal hilum. Large cavitating ulcers may also be seen.

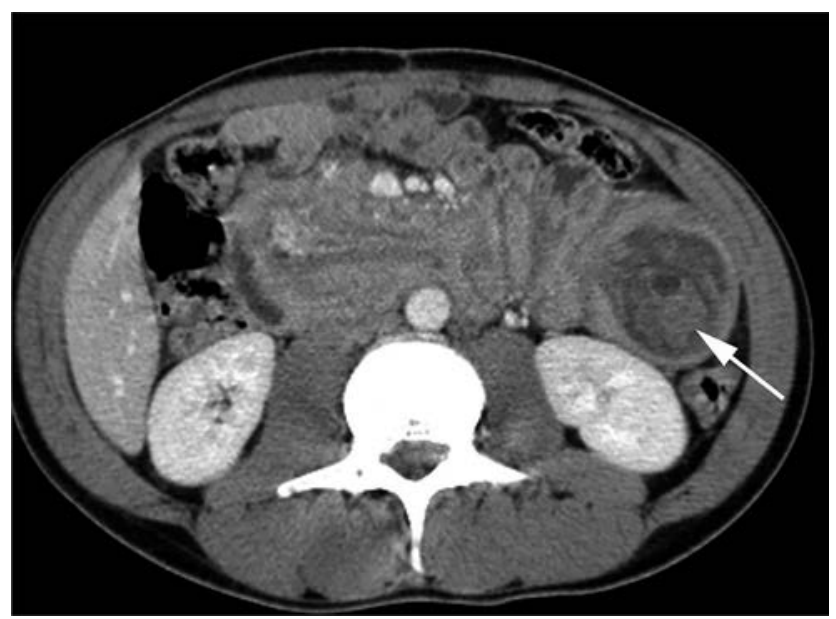

Fig. 10 A small lobulated hamartoma in the duodenum (arrow) presenting with intussusception.

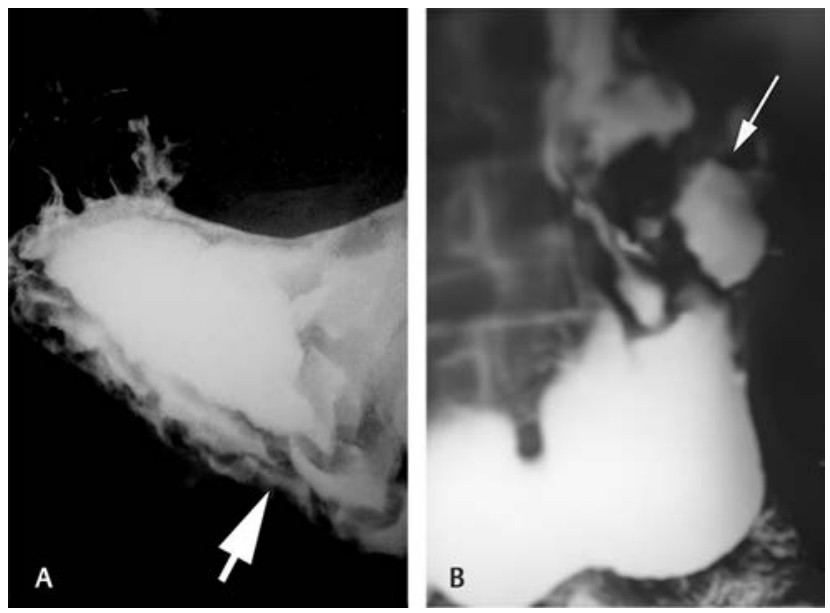

Fig. 11 Lymphoma. (A) Barium meal examination shows thickening of rugal folds (arrow). (B) Large cavitating or aneurysmal ulcer seen in the stomach in lymphoma involvement (arrow).
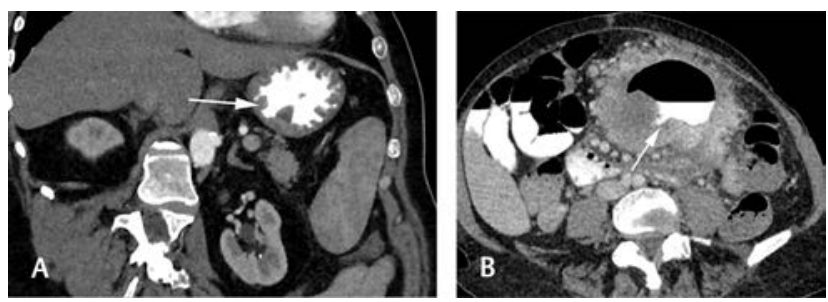

Fig. 12 Lymphoma. (A) Coronal CT image shows thickening of rugal folds (arrow). (B) Axial CT image shows marked thickening of the stomach due to lymphoma with aneurysmal cavitation and dilatation (arrow with multiple lymph nodes around the stomach. CT, computed tomography.

\section{Funding}

None.

\section{Conflict of Interest \\ None declared.}

\section{References}

1 Kang HC, Menias CO, Gaballah AH, et al. Beyond the GIST: mesenchymal tumors of the stomach. Radiographics 2013;33(6):1673-1690

2 Nagtegaal ID, Odze RD, Klimstra D, et al; WHO Classification of Tumors Editorial Board. The 2019 WHO classification of tumors of the digestive system. Histopathology 2020;76(2):182-188

3 Jayaraman MV, Mayo-Smith WW, Movson JS, Dupuy DE, Wallach MT. CT of the duodenum: an overlooked segment gets its due. Radiographics 2001;21(Spec No) :S147-S160

4 Hong X, Choi H, Loyer EM, Benjamin RS, Trent JC, Charnsangavej C. Gastrointestinal stromal tumor: role of CT in diagnosis and in response evaluation and surveillance after treatment with imatinib. Radiographics 2006;26(2):481-495 
5 Sandrasegaran K, Rajesh A, Rushing DA, Rydberg J, Akisik FM, Henley JD. Gastrointestinal stromal tumors: CT and MRI findings. Eur Radiol 2005;15(7):1407-1414

6 Miettinen M, Sarlomo-Rikala M, Lasota J. Gastrointestinal stromal tumors: recent advances in understanding of their biology. Hum Pathol 1999;30(10):1213-1220

7 Levy AD, Remotti HE, Thompson WM, Sobin LH, Miettinen M. Gastrointestinal stromal tumors: radiologic features with pathologic correlation. Radiographics 2003;23(2):283-304, 456, quiz 532

8 Burkill GJC, Badran M, Al-Muderis O, et al. Malignant gastrointestinal stromal tumor: distribution, imaging features, and pattern of metastatic spread. Radiology 2003;226(2):527-532

9 Miettinen M, Lasota J. Gastrointestinal stromal tumors-definition, clinical, histological, immunohistochemical, and molecular genetic features and differential diagnosis. Virchows Arch 2001;438(1):1-12

10 Nilsson B, Bümming P, Meis-Kindblom JM, et al. Gastrointestinal stromal tumors: the incidence, prevalence, clinical course, and prognostication in the preimatinib mesylate era-a population-based study in westernSweden.Cancer 2005;103(4):821-829

11 Hartley N, Rajesh A, Verma R, Sinha R, Sandrasegaran K. Abdominal manifestations of neurofibromatosis. J Comput Assist Tomogr 2008;32(1):4-8

12 Sinha R, Verma R, Kong A. Mesenteric gastrointestinal stromal tumor in a patient with neurofibromatosis. AJR Am J Roentgenol 2004;183(6):1844-1846

13 Agaimy A, Wünsch PH. True smooth muscle neoplasms of the gastrointestinal tract: morphological spectrum and classification in a series of 85 cases from a single institute. Langenbecks Arch Surg 2007;392(1):75-81

14 Lee M-J, Lim JS, Kwon JE, et al. Gastric true leiomyoma: computed tomographic findings and pathological correlation. J Comput Assist Tomogr 2007;31(2):204-208

15 Thompson WM, Kende AI, Levy AD. Imaging characteristics of gastric lipomas in 16 adult and pediatric patients. AJR Am J Roentgenol 2003;181(4):981-985

16 Levy AD, Quiles AM, Miettinen M, Sobin LH. Gastrointestinal schwannomas: CT features with clinicopathologic correlation. AJR Am J Roentgenol 2005;184(3):797-802
17 Miettinen M, Shekitka KM, Sobin LH. Schwannomas in the colon and rectum: a clinicopathologic and immunohistochemical study of 20 cases. Am J Surg Pathol 2001;25(7):846-855

18 Hur BY, Kim SH, Choi JY, et al. Gastroduodenal glomus tumors: differentiation from other subepithelial lesions based on dynamic contrast-enhanced CT findings. AJR Am J Roentgenol 2011;197(6):1351-1359

19 Redvanly RD, Silverstein JE. Intra-abdominal manifestations of AIDS. Radiol Clin North Am 1997;35(5):1083-1125

20 Pantongrag-Brown L, Nelson AM, Brown AE, Buetow PC, Buck JL. Gastrointestinal manifestations of acquired immunodeficiency syndrome: radiologic-pathologic correlation. Radiographics 1995;15(5):1155-1178

21 Ramachandran I, Sinha R, Rajesh A, Verma R, Maglinte DD. Multidetector row CT of small bowel Tumors. Clin Radiol 2007;62(7):607-614

22 Binstock AJ, Johnson CD, Stephens DH, Lloyd RV, Fletcher JG. Carcinoid tumors of the stomach: a clinical and radiographic study. AJR Am J Roentgenol 2001;176(4):947-951

23 Rindi G, Luinetti O, Cornaggia M, Capella C, Solcia E. Three subtypes of gastric argyrophil carcinoid and the gastric neuroendocrine carcinoma: a clinicopathologic study. Gastroenterology 1993;104(4):994-1006

24 Ghai S, Pattison J, Ghai S, O'Malley ME, Khalili K, Stephens M. Primary gastrointestinal lymphoma: spectrum of imaging findings with pathologic correlation. Radiographics 2007;27(5):1371-1388

25 Park M-S, Kim KW, Yu J-S, et al. Radiographic findings of primary B-cell lymphoma of the stomach: low-grade versus high-grade malignancy in relation to the mucosa-associated lymphoid tissue concept. AJR Am J Roentgenol 2002;179(5):1297-1304

26 Smedby KE, Baecklund E, Askling J. Malignant lymphomas in autoimmunity and inflammation: a review of risks, risk factors, and lymphoma characteristics. Cancer Epidemiol Biomarkers Prev 2006;15(11):2069-2077

27 Gossios K, Katsimbri P, Tsianos E. CT features of gastric lymphoma. Eur Radiol 2000;10(3):425-430 